\title{
Methodological Approaches for Strategic Economic Analysis
}

Submitted 23/03/19, $1^{\text {st }}$ revision 12/05/19, $2^{\text {nd }}$ revision 18/06/19, accepted 20/07/19

\author{
N.A. Prodanova ${ }^{1}$, N.S. Plaskova ${ }^{2}$, F.A. Khamkhoeva ${ }^{3}$, \\ R. S. Yandiev ${ }^{4}$, T.Y. Serebryakova ${ }^{5}$, E.A. Ivanov ${ }^{6}$
}

\begin{abstract}
:
Purpose: In the framework of this study, an analysis of domestic experience in the formation of a methodology for conducting strategic economic analysis was carried out.

Design: The behavior of strategic economic analysis, in authors' opinion is defined as a certain process involving several stages, the result of which will be a map for effective strategic business goals.

Findings: The authors have distinguish traditional (statistical), economic-mathematical and special techniques in the system of methods of strategic economic analysis; they emphasize the relevance of tools of strategic economic analysis for a commercial organization operating in modern economic conditions, but they focus on the prospects of development in the field of improvement and expansion of the methodological base of this science.

Practical implications: The authors substantiated the need to include budgeting in the system of methods of strategic economic analysis and developed an algorithm for conducting strategic economic analysis of the activities of a commercial organization.

Originality: As a result of the methodological foundations of strategic economic analysis, a scheme for the correspondence of its methods to the stages of its organization was developed.
\end{abstract}

Keywords: Strategic economic analysis, strategy, system of methods, budgeting.

JEL codes: M21; M40; G32.

Article Type: Research study.

\footnotetext{
${ }^{1}$ Plekhanov Russian University of Economics, Moscow, Russia, prodanova-00@mail.ru

${ }^{2}$ Plekhanov Russian University of Economics, Moscow, Russia.

${ }^{3}$ Ingush state University, Mutalieva str., 221, Nazran, 386105, Republic of Ingushetia, Russia

${ }^{4}$ Institute of Economics and law (Nazran), Republic of Ingushetia, Russia.

${ }^{5}$ Russian University of Cooperation, Moscow, Russia

${ }^{6}$ Chuvash State Agricultural Academy, Cheboksary, Chuvash Republic, Russia
} 


\section{Introduction}

Modern conditions for the functioning of a commercial organization put forward new requirements for the disclosure of information on business performance, which largely determines its investment attractiveness. A special role in the generation of this kind of information, both for external use and for internal management purposes, is played by economic analysis. It is one of the most important components of the management process, which makes it necessary to integrate a scientific approach into it (Korableva et al., 2018).

Economic analysis solves a wide range of managerial tasks and problems, so that it is possible to distinguish different types within the scientific discipline. Conditions of functioning of the commercial organization not only in Russian, but also in the world markets, are unstable. In its turn, the Russian economy is experiencing a recession. The observed decrease in aggregate demand, the tense of the geopolitical situation, unpredictable fluctuations in exchange rates greatly reduce the organization's ability to implement long-term forecasts (Erbilgin, 2017; Areiqat et al., 2019; Korauš et al., 2019).

However, this type of analytical work is necessary to make timely management decisions to optimize costs or, conversely, to attract additional funding. In this regard, the strategic economic analysis becomes an indispensable tool in the arsenal of the manager. The methodological capabilities of this type of research activity are a state-of-the-art in the field of assessing the investment attractiveness of a commercial organization. Clear strategic guidelines for maximizing market value create a user-friendly information platform, that allows you to adequately answer the main questions of concern to investors or other stakeholders planning to invest in an organization.

\section{Literature Review}

The task to improve the methodology of economic analysis was studied by several domestic and foreign scientists as V.I. Barilenko, M. Blaug, L.T. Gilyarovskaya, D.M. Keynes, M.V. Miller, W. Mackenzie, J.A. Schumpeter and others.

The concept of strategic economic analysis, despite the broad prospects in the field of methodological development and testing of practically significant results, is relatively new for domestic science, which is expressed in the ambiguity of both its interpretation and the allocation of its subject area.

Western economists assign a fundamental role to strategic economic analysis. In recent years, the growing interest of the Russian scientific community in this topic has been particularly noted, specifically the question of the need to recognize strategic economic analysis as an independent scientific discipline has been raised. 
Khabirov G.A., Khabirov A.G. and Sitdikova G.Z. (2014) believe that strategic economic analysis serves to interpret the strategic position of a commercial organization. At the same time, the goal of strategic economic analysis is to assess the influence of factors determining the organization's activities in the present and future on its development strategy, which differs significantly from the above approach, where factor analysis serves as the basis for assessing the performance of an organization that reflects the "level of business quality".

Zolotova S.V. (2013) along with other economists believes that strategic economic analysis should be considered as the primary stage of strategic management. Moreover, she notes that the ambiguity of the position of scientists in the perception of strategic economic analysis as an independent type of economic analysis or as a function of management is associated with a similar situation in relation to the economic analysis itself.

Different views of domestic economists on the etymology of the concept of "strategic economic analysis" cause difficulties in a single definition of its essence. One of the authors of this study, Plaskova N.C. (2010) focuses on strategic economic analysis to provide tailored analytical information in order to improve strategic management decisions. Zolotova S.V. (2013) notes the existence of a narrow and broad understanding of the essence of this concept. In a narrow sense, strategic economic analysis serves to form, evaluate and adjust the development strategy adopted by the organization. Broadly, it replaces the concept of prognostic research, acting as a set of theoretical and empirical methods of both retrospective and perspective economic analysis used to predict the further development of an organization without a clear understanding of its strategy.

\section{Methodology}

As part of the study, an analysis of domestic experience regarding the formation of a methodology for conducting strategic economic analysis was carried out. As research tools, a systematic analysis of empirical research, the principles of formal logic, synthesis and analysis of theoretical and practical material were used.

\section{Results}

In our opinion, the formation of a methodology for conducting strategic economic analysis of each organization has its own characteristics that consider the specific features of a business entity. It should be emphasized that it follows from the definition of strategic economic analysis that this concept characterizes a process. Thus, we can talk about a few stages, the result of which will be a map of the strategic business goals of the company such as: 
$\checkmark$ Determination of the General period of formation of the development strategy.

$\checkmark$ Research of external financial environment factors.

$\checkmark$ Evaluation of strengths and weaknesses of activities.

$\checkmark$ Comprehensive assessment of the current position of the organization in the market sector (competitive environment).

$\checkmark$ Formation of strategic corporate goals.

$\checkmark$ Formation of strategic functional goals.

$\checkmark$ Formation of strategic business goals in areas and activities.

$\checkmark$ The development of strategic business goals of individual structural units.

$\checkmark$ Development of targeted strategic standards.

$\checkmark$ Comparison of the effectiveness of the developed strategic alternatives.

$\checkmark$ Creating a set of necessary conditions to ensure the implementation of the strategy.

$\checkmark$ Organization of hierarchical personified control over the implementation of the chosen strategy.

$\checkmark$ Creating a set of measures to effectively respond to the negative impact of external and internal factors.

$\checkmark$ Correction of a balanced system of strategic indicators considering the real impact of external and internal factors.

In addition, each of these stages corresponds to its own unique set of methods. The authors of this research distinguish traditional (statistical), economic-mathematical and special methods in the system of strategic economic analysis. Techniques demanded for strategic economic analysis can be divided into quantitative and qualitative (Korableva et al., 2019). Quantitative methods include those methods whose use is measurable, objective and unambiguous. While the qualitative ones will differ in subjectivity both in the interpretation of the results and in the nature of the performance.

The bulk of the methods of strategic economic analysis belongs to the first group, apart from heuristic methods (expert assessment methods, brainstorming) and most of the special ones (SWOT, PEST, SNW, portfolio, scenario, comparative). The grouping of methods of strategic economic analysis by the criterion of subjectivity is presented in Table 1.

Table 1. The system of methods of strategic economic analysis

\begin{tabular}{|c|c|c|}
\hline \multicolumn{2}{|l|}{ By degree of subjectivity } & \multirow{2}{*}{$\begin{array}{l}\text { By the method of } \\
\text { assessment }\end{array}$} \\
\hline Quantitative & Qualitative & \\
\hline Standard methods & \multirow[t]{2}{*}{-} & \multirow[b]{2}{*}{ Traditional (statistical) } \\
\hline $\begin{array}{l}\text { Methods of deterministic factor } \\
\text { analysis }\end{array}$ & & \\
\hline Classical mathematical analysis & \multirow{2}{*}{ 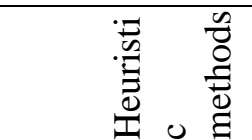 } & \multirow{2}{*}{ 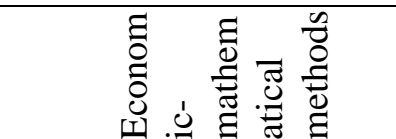 } \\
\hline $\begin{array}{ll}\text { Methods of elementary } \\
\text { mathematics }\end{array}$ & & \\
\hline
\end{tabular}




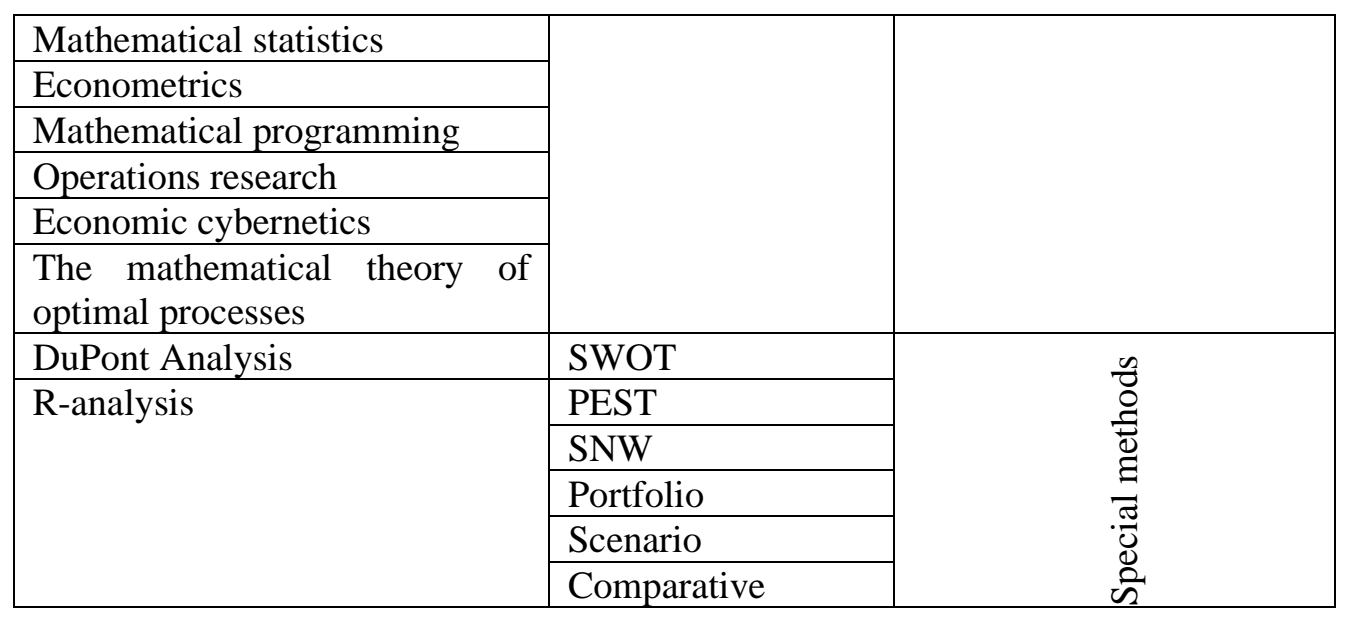

As it is shown in Table 1, the scientific direction described above has an extensive methodological basis.

The demand for strategic economic analysis tools for a commercial organization operating in modern economic conditions justifies the prospects of developments in the field by improving and expanding the methodological base of this science (Arribas et al., 2019; Goryushkina et al., 2018; Yemelyanov et al., 2019; Dyussembekova et al., 2019; Bozhkova et al., 2019; Korchevenkov and Aleksandrova, 2017; Nikolaeva et al., 2018b). In particular, the tasks solved through budgeting necessitate the inclusion of this management technology in the system of strategic economic analysis. Budgeting is "a management technology that provides an increase in the financial soundness of managerial decisions made based on planning and accounting in the budget system for a set of optimal indicators for the future development of an organization, its structures and types of business". (Nikolaeva et al., 2018b).

The budget of a commercial organization is a reliable information base for assessing its investment attractiveness and managing the effectiveness and the efficiency of its activities. Like any other financial plan, a budget can have various time limits. In practice, creating a detailed long-term budget for an organization makes it difficult to predict the external environment (Dunets et al., 2019; Yemelyanov et al., 2018a; 2018b; Cicek et al., 2012; Banerjee and Mistri, 2019; Turen et al., 2019; Olaniyi et al., 2019; Aleksandrova et al., 2019). It can rely on the assumption that in the planning period the company will achieve the necessary financial results, and the scale of its activities and market conditions will not change. Or it is about preparing a laborious and cumbersome system of plans considering all possible forecasts (Dobrovolskienè et al., 2017; Singareddy et al., 2019). Or the organization makes a moral commitment to review the current budget repeatedly. 
However, the most realistic situation remains, in which a detailed budget is prepared only for the nearest planning period, and the indicators for all subsequent ones are adjusted annually taking into account changes in the external environment, as well as in target settings from business owners (Smirnova and Soloviov, 2017; Nikolaeva et al., 2018a). Moreover, the created model of the long-term development of the company is the basis for the development of a new plan along with a detailed analysis of the implementation of the current budget. Budgeting, which necessarily involves monitoring the implementation of the plan, allows you to objectively evaluate the current and predict the future state of affairs in the company. Based on such a forecast, ideas about the attainability of its strategic goals are formed, the course is adjusted, or another alternative to doing business is chosen.

Thus, budgeting should be considered as an important step in strategic planning. However, this management technology cannot be successfully implemented being in isolation from other methods of strategic economic analysis (Monni et al., 2017; Havierniková and Kordoš, 2019; Proshchalykina et al., 2019). We believe that budgeting should be included in the group of special methods of strategic economic analysis.

Regarding the technological features of preparing a long-term budget, it seems to us appropriate to use the budgeting methodology in combination with scenario or Ranalysis, as well as methods of determinate factor analysis. It should be borne in mind that the use of methods of a variety of composition, in contrast to the use of one research method, significantly improves the quality of its results, providing it with additional accuracy.

The above conclusions allow us to consider the budgeting process as one of the methods of strategic economic analysis. This approach is possible in a situation when it comes to assessing the implementation and updating the strategy of a commercial organization. A plan-factual analysis carried out during budgeting allows you to quickly detect deviations in their pure form that are inefficiently spent resources or unaccounted factor influences. Further application of strategic economic analysis contributes to the timely development of new strategic alternatives or revision of the company's course (Mohd and Mohd, 2018; Kilinc et al., 2018; Prakash and Garg, 2019; Aleksandrova et al., 2017a, 2017b; Tung, 2019).

On the other hand, budgeting can have a fundamentally different meaning for a commercial organization, when there is a need to develop and implement a new strategy from scratch (Shatunova et al., 2019). In this case, the existing streamlined budget process provides a powerful information base for the implementation of strategic economic analysis. During the planning process, starting from the strategy, a system of balanced strategic indicators (Balanced ScoreCard) is created, which should be the basis for new budgets. At the same time, the organization faces the question: "Are the given parameters achievable in the current and future nature of the impact of external and internal factors that determine its activity?" In this 
regard, it is advisable to use methods of strategic economic analysis. Budgeting is the basis of strategy adjustment and is part of information support, and the budget is the result obtained based on the developed strategic indicators, in other words, it is a formalization of the strategy. The relationship of budgeting and the strategy of a commercial organization can be represented as follows (Figure 1).

Figure 1. The relationship of the business plan of the project, budgeting and organization strategies

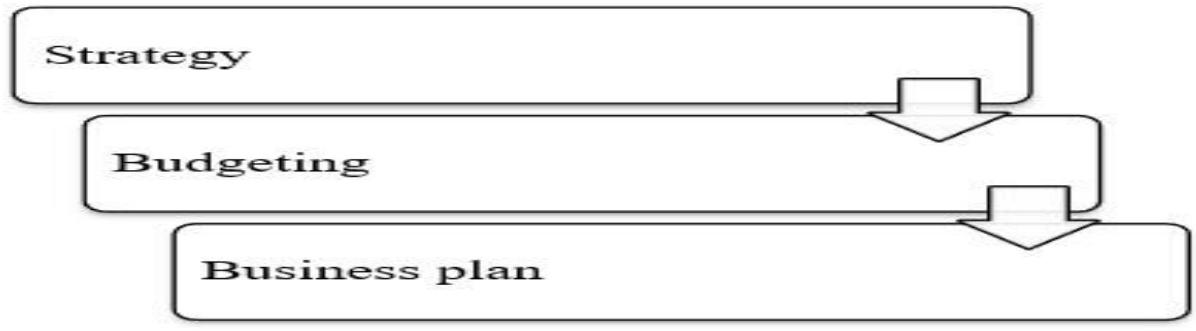

In the presence of a well-functioning system of strategic economic analysis, monitoring of the effectiveness of the strategy can be carried out in an operational mode, which will quickly and adequately respond to any changes in the external and internal environment of the organization. In this regard, the algorithm of the strategic economic analysis of the commercial organization can be presented as follows (Figure 2). At the same time, budgeting is only one of the stages of strategic economic analysis. In addition, it must be borne in mind that its subject area includes the influence of external and internal factors that determine the organization's activities (Bekebayeva et al., 2019). Accordingly, the creation of an adequate information base for making optimal decisions in line with the strategic management of a commercial organization involves a combination of budgeting with other special methods of strategic economic analysis.

As a result of research of the methodological foundations of strategic economic analysis, we developed a scheme for the correspondence of its methods to the stages of its organization (Table 2). At the same time, separate tools correspond to the various stages of strategic economic analysis.

\section{Conclusion}

The methodological approaches proposed for conducting strategic economic analysis complements the approaches that exist today, and can be used in practice to evaluate objects of various organizational and legal forms and types of activities, to justify tactical, strategic managerial decisions and forecasts for the long-term development of companies representing the subject of interest of various user groups of information. Using the proposed algorithm is the basis for a strategically oriented management for the investment attractiveness of a commercial organization. 
Figure 2. The algorithm for conducting strategic economic analysis

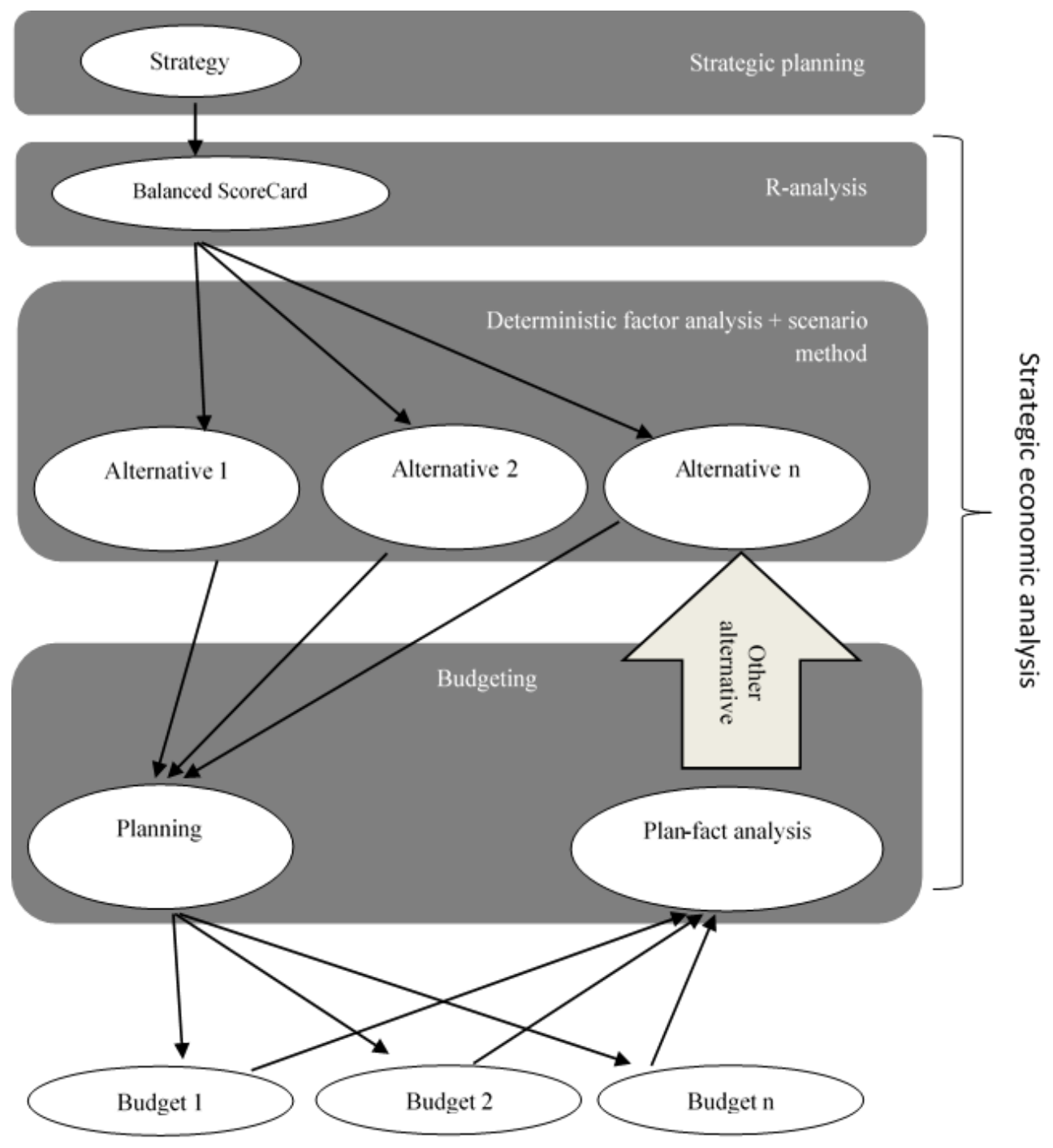

Table 2. Appropriate methods of strategic economic analysis

\begin{tabular}{|l|l|}
\hline Organization stage of strategic economic analysis & $\begin{array}{l}\text { Strategic economic analysis } \\
\text { methods }\end{array}$ \\
\hline $\begin{array}{l}\text { Determination of the general period of formation of a } \\
\text { development strategy }\end{array}$ & Heuristic methods \\
\hline $\begin{array}{l}\text { Research of factors of the external financial } \\
\text { environment }\end{array}$ & PEST analysis \\
\hline Organization strengths and weaknesses assessment & SWOT analysis \\
\hline $\begin{array}{l}\text { Comprehensive assessment of the organization's } \\
\text { current position in the market sector (competitive }\end{array}$ & SWOT analysis \\
\hline
\end{tabular}




\begin{tabular}{|l|l|}
\hline environment) & $\mid$ \\
\hline Formation of strategic corporate goals & $\begin{array}{l}\text { Heuristic methods, quantitative } \\
\text { methods }\end{array}$ \\
\hline Formation of strategic functional goals & Quantitative methods \\
\hline $\begin{array}{l}\text { Formation of strategic business goals by areas and } \\
\text { activities }\end{array}$ & Quantitative methods \\
\hline $\begin{array}{l}\text { The development of strategic business goals of } \\
\text { individual structural units }\end{array}$ & Quantitative methods \\
\hline Development of targeted strategic standards & Quantitative methods \\
\hline $\begin{array}{l}\text { Assessment of the comparative effectiveness of the } \\
\text { developed options for strategic alternatives }\end{array}$ & $\begin{array}{l}\text { R-analysis, deterministic factor } \\
\text { analysis methods, DuPont } \\
\text { analysis, scenario analysis }\end{array}$ \\
\hline $\begin{array}{l}\text { Creation of a set of measures to effectively respond } \\
\text { to the negative impact of external and internal factors }\end{array}$ & $\begin{array}{l}\text { R-analysis, deterministic factor } \\
\text { analysis methods, DuPont } \\
\text { analysis, scenario analysis }\end{array}$ \\
\hline $\begin{array}{l}\text { Correction of a balanced system of strategic } \\
\text { indicators taking into account the real impact of } \\
\text { factors of the external and internal environment }\end{array}$ & $\begin{array}{l}\text { R-analysis, deterministic factor } \\
\text { analysis methods, DuPont } \\
\text { analysis, scenario analysis }\end{array}$ \\
\hline
\end{tabular}

\section{References:}

Areiqat A.Y., Al-Ali A.H., Al-Yaseen, H.M. 2019. Entrepreneurship in palm fronds recycling: a Jordanian case. Entrepreneurship and Sustainability Issues, 6(4), 16941703. http://doi.org/10.9770/jesi.2019.6.4(10)

Aleksandrova, T.N., Nikolaeva, N.V. \& Potemkin, V.A. 2019. Beneficiation of carbonaceous rocks: New methods and materials. Paper presented at the Innovation-Based Development of the Mineral Resources Sector: Challenges and Prospects.11th Conference of the Russian-German Raw Materials, 391-398.

Arribas, I., Espinós-Vañó, M.D., García, F., Tamosiuniene, R. 2019. Negative screening and sustainable portfolio diversification. Entrepreneurship and Sustainability Issues, 6(4), 1566-1586. https://doi.org/10.9770/jesi.2019.6.4(2)

Aleksandrova, T.N. \& Talovina, I.V. 2017a. Platinum-group metals in residual soils and potential efficiency of their processing in gravity concentrators. Journal of Mining Science, 53(3), 553-558. doi:10.1134/S106273911703250X

Aleksandrova, T., Aleksandrov, A. \& Nikolaeva, N. 2017b. An investigation of the possibility of extraction of metals from heavy oil. Mineral Processing and Extractive Metallurgy Review, 38(2), 92-95. doi:10.1080/08827508.2016.1262860

Banerjee, R. \& Mistri, B. 2019. Impact of coal mining in diversification of rural livelihoods: A case study in the barjora colliery area of bankura district, west bengal. Space and Culture, India, 6(5), 228-240. doi:10.20896/SACI.V6I5.335

Bekebayeva, A.D., Nurbayev, Z.E., Nursultanova, L.N., Azmukhanova, A.M. \& Yerimbetova, K.M. 2019. Formation and development of women's nongovernmental organisations in central asia. Space and Culture, India, 6(5), 136-155. doi:10.20896/saci.v6i5.480.

Bozhkova, G.N., Shastina, E.M., Kalimullina, O.V., Shatunova, O.V. 2019. Study of literary images of gifted characters in optional activities as a mean to develop capable and talented youth. Space and Culture, India, Vol. 7:1, 264- 273.

https://doi.org/10.20896/saci.v7i1.463 
Blaug, M. 2008.100 great economists before Keynes. M. Blaug, transl. from English, ed. A.A. Fofonova. $\mathrm{SPb}$.: School of Economics, 352.

Cicek, V., Ulker, R. \& Tarman, B. 2012. Comparison of character education in US and turkish educational systems: Globalizing american education system. Energy Education Science and Technology, Part B: Social and Educational Studies, 4(3), 1311-1322.

Dobrovolskienè, N., Tvaronavičienè, M., Tamošiūnienè, R. 2017. Tackling projects on sustainability: A Lithuanian case study. Entrepreneurship and Sustainability Issues, 4(4), 477-488. http://doi.org/10.9770/jesi.2017.4.4(6)

Dunets, A., Latysheva, O., Bitter, N., Vakhrushev, I., Shichiyakh, R. \& Zhuruli, G. 2019. The economic and infrastructural basis for the development of tourist space: The essence, structure and typology. Journal of Environmental Management and Tourism, 10(2), 319-327. doi:10.14505/jemt.v10.2(34).05

Dyussembekova, G., Reshina, G., Primbetova, S., Sultanova, M. \& Beisembayeva, G. 2019. Role and importance of the damu enterprise development fund and international investment funds in implementing project and leasing financing programs in kazakhstan. Space and Culture, India, 6(5), 156-165. doi:10.20896/saci.v6i5.442

Erbilgin, E. 2017. A comparison of the mathematical processes embedded in the content standards of Turkey and Singapore. Research in Social Sciences and Technology, 2(1), 53-74.

Goryushkina, N.E., Vakhrushev, I.B., Akhmetova, M.K., Otto, O.V., Pesotskaya, E.V. \& Voinova, N.E. 2018. The world hotel market: Current state and development trends. International Journal of Mechanical Engineering and Technology, 9(12), 618-627.

Havierniková, K., Kordoš, M. 2019. Selected risks perceived by SMEs related to sustainable entrepreneurship in case of engagement into cluster cooperation, Entrepreneurship and Sustainability Issues, 6(4), 1680-1693. http://doi.org/10.9770/jesi.2019.6.4(9)

Khabirov, A.G., Khabirov, G.A., Sitdikova, G.Z. 2014. Strategic economic analysis as the basis for the formation of strategic management decisions in commercial organizations in the agricultural sector of the economy. Scientific fundamentals development strategies of agribusiness and rural areas in the WTO: materials of the international. scientific-practical conference dedicated to the 70th anniversary of the VolgaU. Volgograd, $164-170$.

Korableva, O.N., Kalimullina, O.V., Zaytseva, A.A. \& Larionov, A.I. 2018. Elaboration of database for the subject domain of innovation and economic growth potential. Paper presented at the Proceedings of the 31st International Business Information Management Association Conference, IBIMA 2018: Innovation Management and Education Excellence through Vision 2020, 6065-6073.

Korableva, O.N., Kalimullina, O.V., Mityakova, V.N. 2019. Designing a System for Integration of Macroeconomic and Statistical Data Based on Ontology. Advances in Intelligent Systems and Computing, 157-165.

Korchevenkov, S.A. \& Aleksandrova, T.N. 2017. Preparation of standard iron concentrates from non-traditional forms of raw material using a pulsed magnetic field. Metallurgist, 61(5-6), 375-381. doi:10.1007/s11015-017-0503-z.

Korauš, A., Gombár, M., Kelemen, P., Backa, S. 2019. Using quantitative methods to identify insecurity due to unusual business operations. Entrepreneurship and Sustainability Issues, 6(3), 1101-1012. http://doi.org/10.9770/jesi.2019.6.3(3)

Kilinc, E., Tarman, B. \& Aydin, H. 2018. Examining turkish social studies teachers' beliefs about barriers toTechnology integration. TechTrends, 62(3), 221-223. doi:10.1007/s11528-018-0280-y. 
Mackenzie, V. 2006. Use and interpretation of financial statements. Translated from English scientific ed. G.V. Grigoras. Dnepropetrovsk: Balance Business Books.

Mohd-Tahir, Z. \& Mohd-Salleh, N. 2018. Effectiveness of Coaching by School Improvement Partners through Good Relationship and Professionalism Skills Practiced. Research in Social Sciences and Technology, 3(1), 16-35. http://ressat.org/index.php/ressat/article/view/339

Monni, S., Palumbo, Tvaronavičienè, M. 2017. Cluster performance: an attempt to evaluate the Lithuanian case. Entrepreneurship and Sustainability Issues, 5(1), 43-57. http://doi.org/10.9770/jesi.2017.5.1(4)

Nikolaeva, N.V., Aleksandrova, T.N. \& Elbendari, A.M. 2018a. Ore strength property evaluation in the design of ore preparation cycles. Paper presented at the Geomechanics and Geodynamics of Rock Masses, 1, 333-338.

Nikolaeva, N., Aleksandrova, T. \& Romashev, A. 2018b. Effect of grinding on the fractional composition of polymineral laminated bituminous shales. Mineral Processing and Extractive Metallurgy Review, 39(4), 231-234. doi:10.1080/08827508.2017.1415207.

Olaniyi, O.E., Prause, G., Bakkar, Y. 2019. Entrepreneurial compliance opportunities for maritime fuel producers. Entrepreneurship and Sustainability Issues, 6(4), 15501565. https://doi.org/10.9770/jesi.2019.6.4(1).

Prakash, R., Garg, P. 2019. Comparative assessment of HDI with Composite Development Index (CDI). Insights into Regional Development, 1(1), 58-76. https://doi.org/10.9770/ird.2019.1.1(5).

Proshchalykina, A., Kyryliuk, E., Kyryliuk, I. 2019. Prerequisites for the development and prospects of organic agricultural products market. Entrepreneurship and Sustainability Issues, 6(3), 1107-1117. http://doi.org/10.9770/jesi.2019.6.3(18).

Plaskova, N.S. 2010. Strategic and current economic analysis: an MBA textbook. M.: EKSMO, pp. 633.

Plaskova, N.S. 2007a. Methodology of strategic analysis of business performance. M.: Creative Economy, pp. 254.

Plaskova, N.S. 2007b. Strategic analysis in the organization's business planning system. In N.S. Plaskova, Audit and financial analysis, M.: Publishing house "DSM Press", No. 5, 360-364.

Plaskova, N.S., Petrushina, L.O. 2016. Budgeting as the basis of strategic economic analysis of the activities of a commercial organization. Management accounting, 3, 95-104.

Shatunova, O., Anisimova, T., Sabirova, F., Kalimullina, O. 2019. STEAM as an Innovative Educational Technology. Journal of Social Studies Education Research, 10(2), 131144.

Singareddy, R.R.R., Ranjan, P., Balamurugan, A. \& Shabana, C. 2019. Financial inclusion remodeling: Including the excluded masses. Space and Culture, India, 6(5), 178188. doi:10.20896/SACI.V6I5.375.

Smirnova, N.N. \& Soloviov, V.B. 2017. Some aspects of technology improvement of underground coal gasification. Journal of Industrial Pollution Control, 33(1), 873877.

Tung, L.T. 2019. Role of Unemployment insurance in Sustainable development in Vietnam: Overview and policy implication. Entrepreneurship and Sustainability Issues, 6(3), 1039-1055. http://doi.org/10.9770/jesi.2019.6.3(6).

Turen, S., Abdulla, M., Farooq, M.O., Elsoud, M.S.A. 2019. Causes of Non-Performing Loans: The Experience of Gulf Cooperation Council Countries. Entrepreneurship 
and Sustainability Issues, 6(4), 1955-1974. http://doi.org/10.9770/jesi.2019.6.4(29).

Yemelyanov, V.A., Fatkulin, A.R., Nedelkin, A.A., Titov, V.A. \& Degtyarev, A.V. 2019.

Software for weight estimation of the transported liquid iron. Paper presented at the Proceedings of the 2019 IEEE Conference of Russian Young Researchers in Electrical and Electronic Engineering, ElConRus, 381-384.

doi:10.1109/EIConRus.2019.8657011.

Yemelyanov, V.A., Tochilkina, T.E., Vasilieva, E.V., Deeva, E.A., Nedelkin, A.A. \& Shved, E.V. 2018a. Information technology of monitoring technical condition of torpedo ladle cars based on neural networks. Paper presented at the Journal of Physics: Conference Series, 1118(1). doi:10.1088/1742-6596/1118/1/012051.

Yemelyanov, V., Yemelyanova, N. \& Nedelkin, A. 2018b. Diagnostic system to determine lining condition. Paper presented at the MATEC Web of Conferences, 172. doi:10.1051/matecconf/201817204001.

Zolotova, S.V. 2013. Recognition of strategic economic analysis as an independent scientific discipline. Actual problems of economic sciences, 31, 252-256. 